\title{
Implementation of Random Shuffle Algorithm in "Hangbit" Education Games
}

\author{
Amelia Yusnita* id \\ STMIK Widya Cipta Dharma, \\ Samarinda, 75123, Indonesia \\ amelia@wicida.ac.id \\ * Corresponding author
}

\author{
Pajar Pahruddin \\ STMIK Widya Cipta Dharma, \\ Samarinda, 75123, Indonesia \\ pajar@wicida.ac.id
}

\author{
Theana Dwi Aprillita \\ STMIK Widya Cipta Dharma, \\ Samarinda, 75123, Indonesia \\ theana_dwie@yahoo.co.id
}

Received: 2020-12-01; Revised: 2021-04-12; Accepted: 2021-05-20; Published: 2021-06-01

\begin{abstract}
Learning Media for Carnivorous Animals, Herbivorous Animals, Omnivorous Animals with PCbased Problem Randomization, an application designed to help students understand the introduction of carnivorous, herbivorous and omnivorous animals. The purpose of this study was to assist teachers in teaching lessons on introduction to carnivores, herbivores and omnivores, which consisted of animation, sound and text. This application was built using SwishMax4 and with the Shuffle Random Algorithm on learning questions so that it does not become a monotonous and predictable game. This study produces a multimedia application for learning advice on the introduction of carnivorous, herbivorous and omnivorous animals, so this learning medium is for children aged 7-10 years. The results of the study were tested on students of SD Negeri 010 Samarinda City by demonstrating the program and trying its application. The results of the making of this learning media are Swf.
\end{abstract}

Keywords- Carnivores, Herbivores, Omnivores, Shuffle Random Algorithm.

\section{INTRODUCTION}

Games or games are one of the applications of technology in the electronic field that can provide entertainment for its users. (Auliawati, 2015; Chandra, 2011) Over time, various game genres continue to emerge, some of which are improvements or developments from old genres, some are new and some are a combination of several existing genres. All this makes the game more varied with various kinds of advantages, and more and gamer products are appearing.

Apart from being a medium of entertainment, games can be a learning medium to improve brain development. Endgame provides a great opportunity to stimulate children's thinking. Endgame is a type of game that is used to provide learning to its users through easy-tounderstand game media.

So far, the system of teaching and learning activities carried out by SD Negeri 019 Samarinda Ulu is by using a guidebook which is also used as an exercise book for students and as a medium for teacher learning in carrying out activities. However, the increasing technological developments make children lazy to learn and tend to want to play more. Therefore, to increase the interest in children to learn, it is necessary to have an update in their learning method, namely the learning media through the educational game "Implementation of the Shuffle Random Algorithm in" Hangit "Educational Games. This endgame uses shuffle shuffling logic so that players cannot memorize the positions of playing questions and is a good learning method among children.

Old genres, some new genres and some combinations of several existing genres. All this makes the game more varied with various kinds of advantages, and more and gamer products are appearing. Apart from being a medium of entertainment, games can be a learning medium to improve brain development. Endgame provides a great opportunity to stimulate children's thinking. Endgame is a type of game that is used to provide learning to its users through easy-to-understand game media (Nugroho, 2010; Nurdiansyah, 2016).

So far, the system of teaching and learning activities carried out by SD Negeri 019 Samarinda Ulu is by using a guidebook which is also used as an exercise book for students and as a medium for teacher learning in carrying out activities. However, the increasing technological developments make children lazy to learn and tend to want to play more. Therefore, to increase the interest in children to learn, it is necessary to have an update in their learning method, namely the learning media through the educational game "Implementation of the Shuffle Random Algorithm in" hang bit "Educational Games. This endgame uses shuffle logic so that players cannot memorize the position of playing questions and is a good learning method among children. (Samuel, 2010; Yousnelly, 2015).

\section{LITERATURE REVIEW}

\section{A. Game}

In Indonesian, game is defined as a game. Games are complex activities in which there are rules, play and culture. A game is a system where the player is involved in an artificial conflict, here the player interacts with the system and the conflict in the game is engineered or artificial. (Ismail, 2010; Ramadan, 2010).

\section{B. Shuffle Logic Algorithm}

According to Andrea (2015), Shuffle random is the randomization of the index sequence from a record or array. Shuffling is like shuffling the deck of cards, where all the cards are shuffled so that the order is shuffled. 
Another example, suppose $\mathrm{A}$ is an array of $5 \times 1, \mathrm{~A}=\left[\begin{array}{ll}1 & 2\end{array}\right.$ 345 ] then the random shuffle process will randomize the index array from array A to $\mathrm{A} 1=\left[\begin{array}{lllll}5 & 1 & 3 & 2 & 4\end{array}\right]$ or into another array. In the programming language the random shuffle function can not only randomize numbers, but also can randomize an array of strings or a mixture of strings and numbers (Pressman, 2010; Sari, 2017).

\section{RESEARCH METHODS}

\section{A. hang bit Use Case Diagram}

In Picture 2 it can be seen that players can perform several actions before starting the game (Binanto, 2010; Salahuddin, 2014). In the main menu players can select the learning button which will display an explanation of carnivores, herbivores and omnivorous animals, the how to play button that will display the playing procedure and the play button to start the game. The following is a Use Case Diagram. The hang bit Game design can be seen in Picture 2.

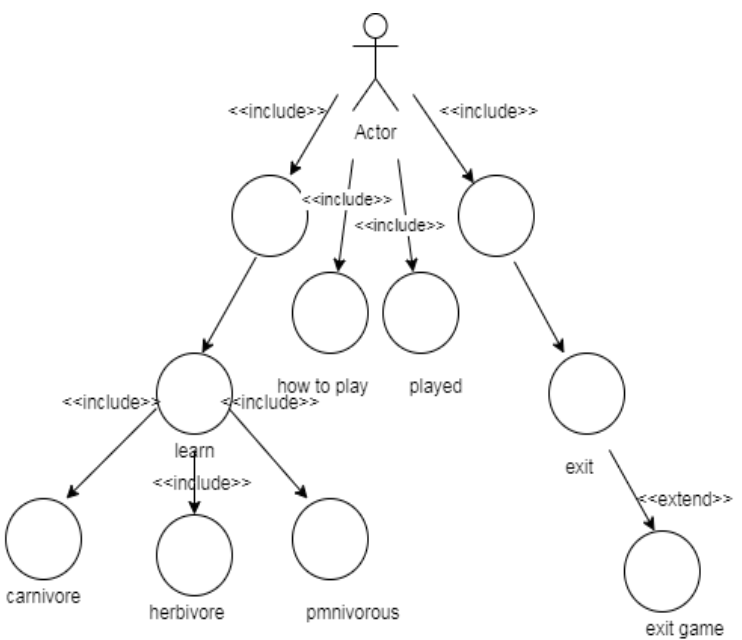

Picture 2. Use Case Diagram on "hang bit"

\section{B. hang bit Game Activity Diagram}

Picture 3 explains the flow of activities that occur when the user selects the play button on the main menu. When the user selects the play button, the system will immediately display the playing scene to start the game. (Handriyantini, 2010; Madcoms, 2010). The following is an Activity Diagram. The design of the hang bit Game can be seen in Picture 3:

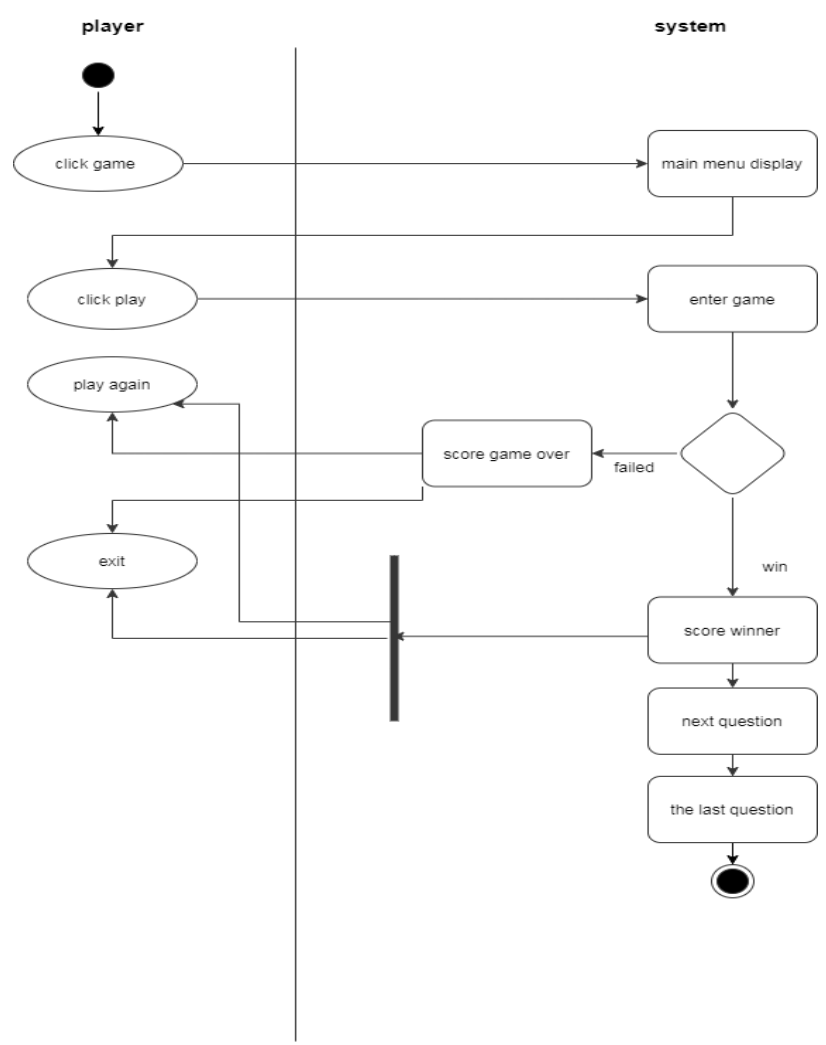

Picture 3. Activity Diagram on "hang bit"

\section{C. hang bit Game Sequence Diagram}

Picture 4 shows the process that occurs between the user and the system, seen in the Sequence Diagram of this endgame, it can be seen that the user enters the main menu scene (Devis, 2015; Dewi, 2012). Then the user selects the play button on the main menu. After that, the playing scene contained in this endgame will appear. if the game is over then the player will exit this game.

The following is a Sequence Diagram. The hang bit Game design can be seen in Picture 4: 


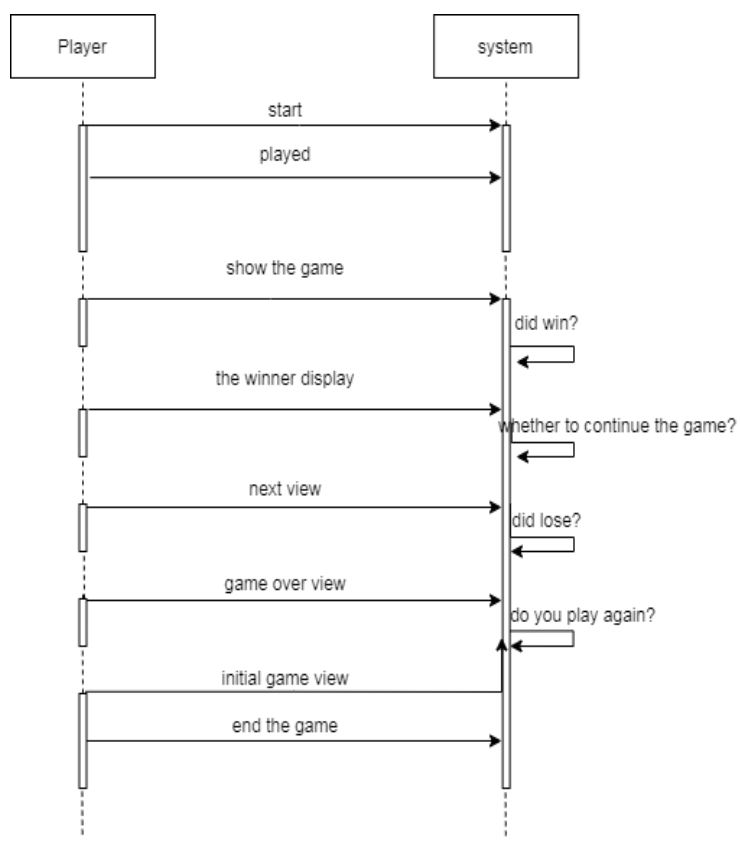

Picture 4. Activity Diagram on "hang bit"

\section{RESULTS AND DisCUSSION}

In this game, players will be given a question with categories, namely carnivores, herbivores and omnivores, and the player's task is to guess the answer. If in guessing the answer, the player chooses 26 possible letters and if the player chooses the wrong letter 4 times, the game will be over.

\section{A. Main Menu Scene}

In Picture 5 the Main Menu Scene is the main view of "hang bit" when a new player enters the system. There is a button menu display of "hang bit". Each button on the main menu scene has its own function, when we click the Learning button the Learning scene will be displayed, when we click the How to Play button the How to Play scene will appear, when we click the Play button the Play scene will be displayed, when we click the sound button will issue a sound that attracts the attention of the player and when we click the exit button it will exit the application. The main menu scene can be seen in Picture 5 .

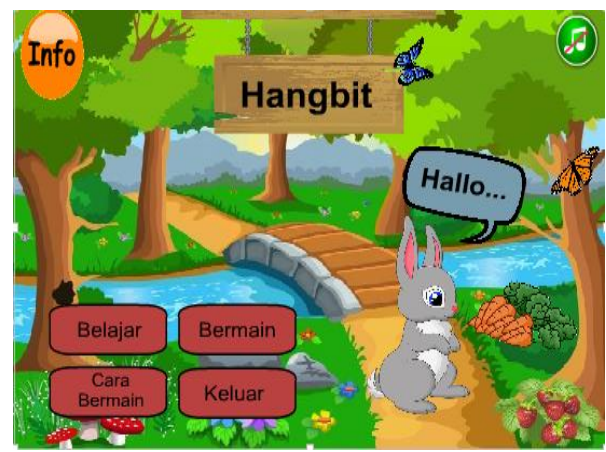

Picture 5. Main Menu Scene

\section{B. Scene Menu Learning}

In Picture 6, the Learning Options Scene has a carnivore button, when the carnivore button is clicked, the names of the carnivorous animals will appear. Herbivore button when the herbivore button is clicked, the names of the herbivore animals will appear, and the omnivore button when the omnivore button is clicked, the names of the omnivore animals will appear.

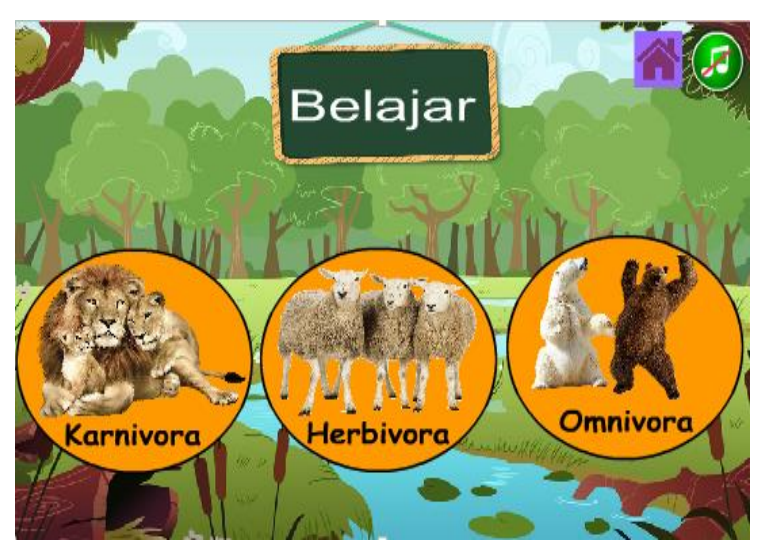

Picture 6. Scene Menu Learning

\section{Carnivorous Animal Learning Scene}

In Picture 7, the Carnivore Animal Learning Scene is a scene where the user can see, understand and study the content of the existing material, making it easier for the user to answer the questions given to the playing scene later.

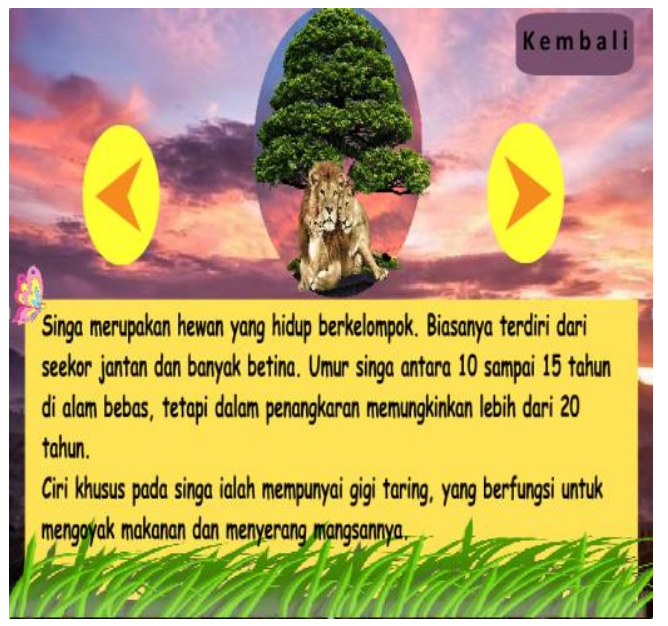

Picture 7. Animal Learning Scene for Carnivore

\section{Herbivorous Animal Learning Scene}

In Picture 8, the Herbivorous Animal Learning Scene is a scene where the user can see, understand and study the content of the existing material, making it easier for the user to answer the questions given to the playing scene later. 


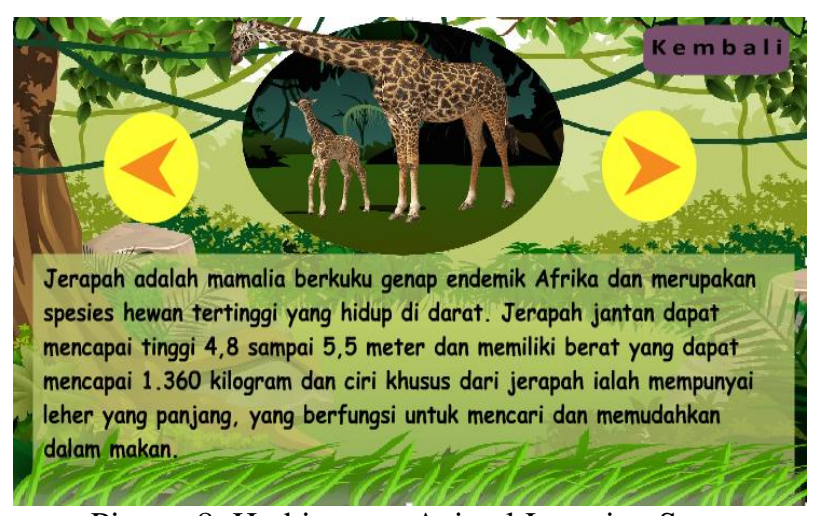

Picture 8. Herbivorous Animal Learning Scene

\section{E. Omnivorous Animal Learning Scene}

In Picture 9, the Omnivorous Animal Learning Scene is a scene where the user can see, understand and study the content of the existing material, making it easier for the user to answer the questions given to the playing scene later.

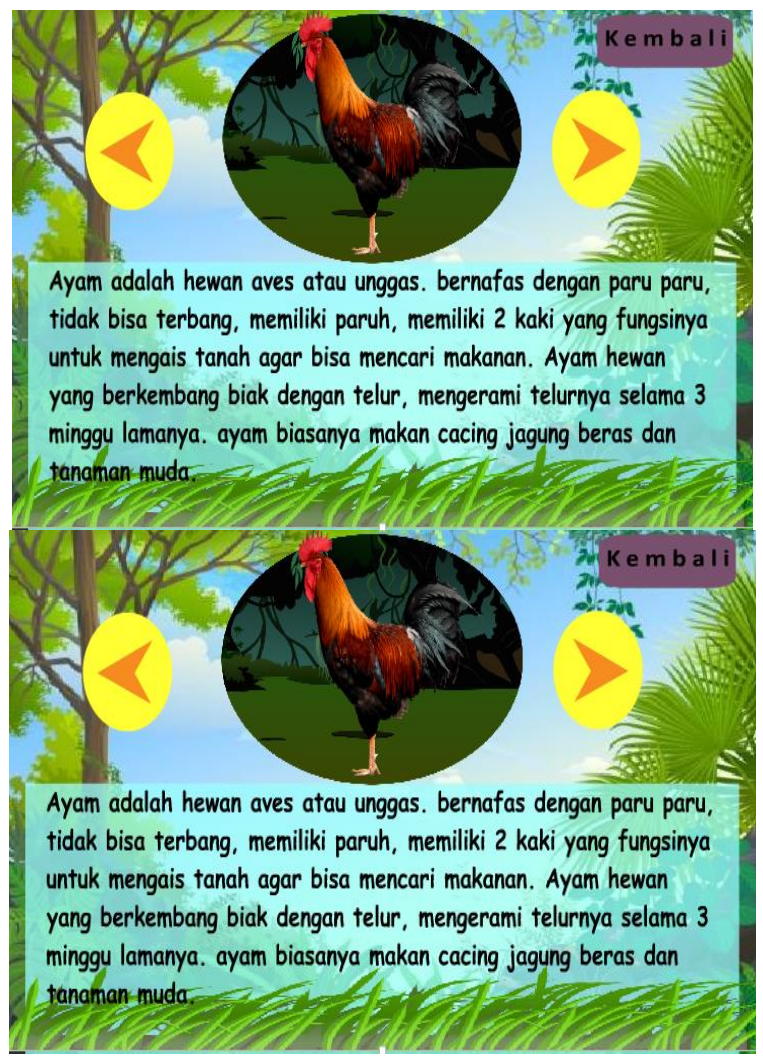

Picture 9. Omnivorous Animal Learning Scene

\section{F. Learning Scene}

In Picture 10 the How to Play Scene can be seen that the how to play menu display shows an explanation of how to play. The aim is that the player can understand the game well and also the back button which leads directly back to the main menu.

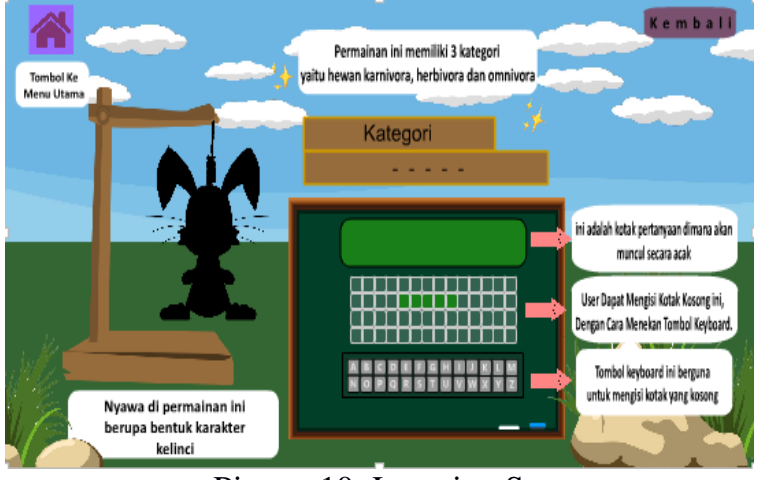

Picture 10. Learning Scene

\section{G. Playing Scene}

In Picture 11, the Play Scene is a scene that will display the practice questions. There are 4 lives in the form of a hanging rabbit character, if you answer incorrectly, the rabbit character will become colored. And there are also categories of carnivorous, herbivorous or omnivorous animals that will appear.

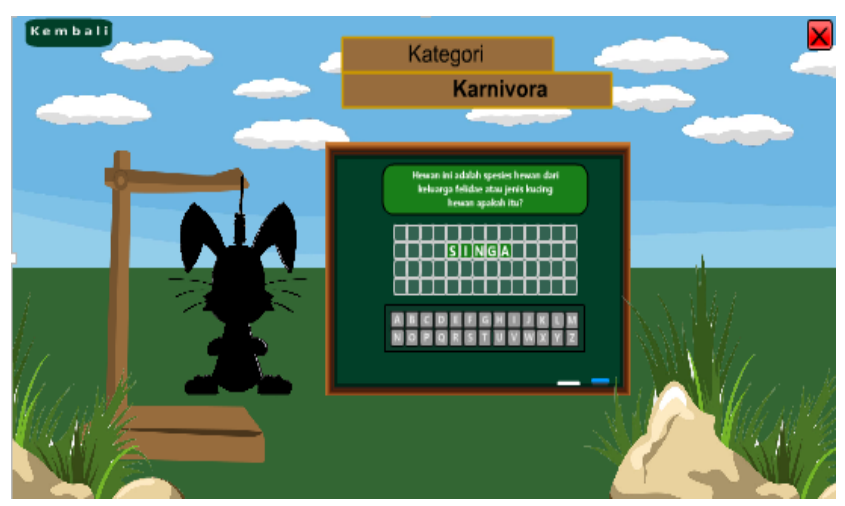

Picture 11. Playing Scene

\section{H. Game Over Scene}

In Picture 4.12, the Game Over Scene is a scene where the player answers incorrectly 4 times.

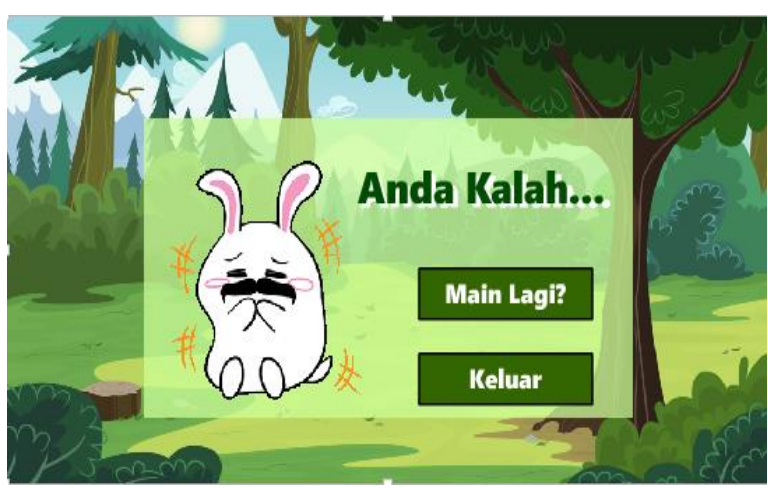

Picture 12. Game Over Scene 


\section{Scene Winner}

In Picture 13, Winner Scene is the scene when the player successfully finishes the game.

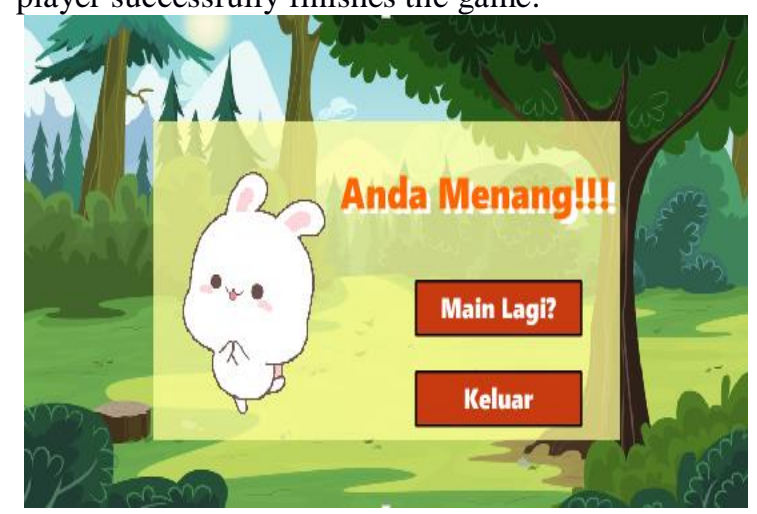

Picture 13. Scene Winner

\section{CONCLUSION}

The concept of "hang bit" is a game that can help children get to know carnivores, herbivores and omnivores, so this lesson is made for children aged 7-10 years. This learning uses an algorithm of randomizing the position of the game questions or it can be called a random shuffle which functions to randomize the questions so that the player cannot remember the order of the questions in the game.

The game cannot be paused while the game is in progress. The learning material in the game discusses carnivorous animals, herbivorous animals, and omnivorous animals. It is hoped that this game can be run on other devices such as cellphones so that it is more practical in use because it can be carried and played anywhere rather than a PC. For the development of this game, it is hoped that it will be more complete, such as adding animals and animations to make it more interesting and the development of additional functions in the game such as pause, score, time, serial number of questions, narration on learning and animal sounds are added so that it is more interesting. The learning menu is made more diverse and even more interesting. The practice menu is added with different question forms. Make 5: 3 shuffling questions (out of 15 questions only 5 are shown).

\section{REFERENCES}

Andrea, R. 2015. Position Randomization TechniquesFind Me The Game Proceedings of the Good. Samarinda: Unmul Press.

Auliawati, P. 2015. Building a Basic English Education Game for Children "Neko The Explorer: Fun With English". Samarinda: STMIK Widya Cipta Dharma.

Binanto, I. 2010. Basic Digital Multimedia Development. Yogyakarta: Andi.

Chandra, 2011. Professional Text Animation with Swishmax. PT: Maxicom, Palembang.

Devis, KB 2015. Building the "Boni Kids- Borneo Animal Kids" Endgame. Samarinda: STMIK Widya Cipta Dharma.
Dewi, GPF 2012. Development of Educational Games on Animal Name Recognition in English as Learning for Elementary School Students Based on Macromedia Flash. Samarinda: STMIK Widya Cipta Dharma.

Handriyantini. 2010. Educative Games (Computer Based Educational Games) For Elementary School Students. Malang: Journal of Informatics \& Computer College.

Ismail, A. 2010. Education Games. Yogyakarta: Proumedia.

Madcoms, 2010. Creative with Adobe Flash CS 5 Professional, Yogyakarta: Andi.

Nugroho, A. 2010. Object-Based Software Engineering using the USDP Method. Yogyakarta: Andi.

Nurdiansah, W. 2016. Kabayan Saving Our Culture 2D Game Application Development. Bandung: Indonesian Computer University.

Pressman, RS 2010. Software Engineering: A Practitioner Approach. Yogyakarta: Andi.

Sari, SI 2017. Building "Sea Animals" Learning Marine Animals by Implementing the Android-Based Shuffle Random Algorithm. Samarinda: STMIK Widya Cipta Dharma.

Saladin. 2014. Learning Module: Software Engineering (Structured and Object Oriented). Bandung: Modula Bandung.

Ramadhan, A. 2010. Processing Audio and Mp3 with Audacity. Jakarta: Elex Media Komputindo.

Samuel, H. 2010. Smart with Games. Jakarta: Gramedia.

Yousnelly, 2015. Natural Science 2 Elementary School Class II. Jakarta: Yudhistira. 